\title{
To promote the engineering innovative abilities of undergraduates by taking projects as the guidance and competitions as the promotion
}

Yishen Xu, Di Wu, Daqing Chen, Jihua Gu, Lei Gao

Yishen Xu, Di Wu, Daqing Chen, Jihua Gu, Lei Gao, "To promote the engineering innovative abilities of undergraduates by taking projects as the guidance and competitions as the promotion," Proc. SPIE 10452, 14th Conference on Education and Training in Optics and Photonics: ETOP 2017, 1045240 (16 August 2017); doi: 10.1117/12.2266119

EDEent: 14th Conference on Education and Training in Optics and Photonics, ETOP 2017, 2017, Hangzhou, China 


\title{
To promote the engineering innovative abilities of undergraduates by taking projects as the guidance and competitions as the promotion
}

\author{
Yishen $\mathrm{Xu}^{*}$, Di Wu, Daqing Chen, Jihua Gu, Lei Gao \\ College of Physics, Optoelectronics and Energy, Soochow University, Suzhou 215006, China
}

\begin{abstract}
According to the inherent requirements of education for talents' knowledge, quality and comprehensive ability and the major training goals of optoelectronics information science and engineering, in order to enhance the undergraduates' comprehensive practical ability and consciousness of innovation, we carried out the reforms of teaching method and teaching mode, which took the training programs of innovation and entrepreneurship for undergraduates, extracurricular academic research fund, "Chun-Tsung Scholar" program or research projects of their tutors as the guidance, and took the all levels of relevant discipline competitions as the promotion. And the training mainline of engineering innovation talents as "undergraduate's tutorial system $\rightarrow$ innovative training program or tutor's research project $\rightarrow$ academic competition $\rightarrow$ graduation projects (thesis)" was constructed stage by stage by combining the undergraduates' graduation projects and their participated academic competition into one for improving the quality of the graduation projects (thesis). The practical results of the last several years illuminate that the proposed training model can effectively stimulate the students' awareness of autonomous learning, enhance their comprehensive ability of analyzing and solving problems and improve their ability of engineering practice and innovation as well as their teamwork spirit.
\end{abstract}

Keywords: reform of training model, engineering practice, project, academic competition, autonomous learning

\section{INTRODUCTION}

There are many problems in the traditional talents training mode, such as centered on imparting knowledge, eager for quick success and instant benefits, the rigid and the single talent standards, the inflexible and same cultivation methods, the one-sided students' development and so on. It is unable to meet the inherent requirements of education for the cultivation of talents, quality and comprehensive ability. What is more, it is not in line with the spirit of "Outline of National Medium and Long-Term Program for Education Reform and Development (2010-2020)" in the training of higher education talents, which focuses on expanding the scale of practical, inter-disciplinary and skilled talents. Apart from this, it is incapable to achieve the training objectives required by engineering professionals. Therefore, it is imperative to change the education principles, reform the talent training mode and accelerate the training of the engineering innovation talents with the relative shortage of major fields for colleges and universities.

Over the past decade, college of physics, optoelectronics and energy of Soochow University actively promote the reform of talent training model. Through the implementation of undergraduate tutor mechanism, using flexible and diverse training methods, building three-dimensional practice teaching system, reforming training programs, curriculum system and assessment methods and other initiatives, the training mainline of engineering innovation talents as "undergraduate's tutorial system $\rightarrow$ innovative training program or tutor's research project $\rightarrow$ academic competition $\rightarrow$ graduation projects (thesis)" was constructed stage by stage, improving the talents' training quality continuously.

\section{REFORM MEASURES}

\subsection{Strengthen students' autonomous learning and innovation consciousness}

First of all, in the process of implementing undergraduate tutor mechanism, teachers introduce the development and construction status of majors, professional training objectives, the main learning content, professional characteristics, industry development and future employment or research direction for the new students, render them a clear understanding of their own profession at the beginning of college life. In addition, in order to stimulate students' interest in learning, sense of responsibility, spirit of autonomous learning and sense of urgency, cultivate students' awareness of

*xys2001@suda.edu.cn

14th Conference on Education and Training in Optics and Photonics: ETOP 2017, edited by Xu Liu,

Xi-Cheng Zhang, Proc. of SPIE Vol. 10452, 1045240 - @ 2017 ICO, IEEE, OSA, SPIE

CCC code: $0277-786 \mathrm{X} / 17 / \$ 18 \cdot$ doi: $10.1117 / 12.2266119$ 
innovation and establish ambitious goals, organize students to visit the laboratory, show the results of scientific research projects and carry out "'anti-push' university career planning" among students.

\subsection{Use flexible and diverse training methods}

Aiming at the goal of cultivating engineering innovation talents, the subject courses with background of engineering are encouraged and demanded to explore discussion and heuristic teaching, experiment-driven teaching, cooperative teaching actively, which could make students "practice while learning" and stimulate students' interest, train students' autonomous learning habit and utilize subject knowledge to solve practical problems of engineering and innovative thinking, guiding student's research, helping them explore the professional related modules or development kits step by step and solving various technical problems encountered in their learning process at the same time. In addition, the student's ability of extracting keywords from the fault phenomenon and then using powerful web search engine are cultivated. The related professional forums and some modern tools which could solve the general professional problems are trained for internalizing the professional knowledge and technologies into their learning ability and comprehensive qualities.

\subsection{Build the three-dimensional practice teaching system}

Several approaches for setting up a three-dimensional practice teaching system, which could support and promote each other, can be summarized as follows: optimizing and development of the experimental content in theoretical course; construction of individual experiments, comprehensive curriculum experiments, professional comprehensive experiment, comprehensive disciplines, interdisciplinary experiments and other practical courses; project-based practice teaching and discussion-based practice teaching; combination of routine experiments and opening experiments, combination of experimental teaching and scientific research, combination of experimental courses and industry practice, combination of independent design and cooperative inquiry, combination of competition design and product development, and other methods. At the same time, students will be encouraged and assisted to apply for and complete all levels of college student innovation and entrepreneurship training program, college students extracurricular academic research fund projects and "Chun-Tsung Scholar". Students' access to literature, access to important information, and the ability to analyze, summarize, and solve problems are further developed. The combination of boring, abstract, discrete theoretical knowledge and engineering practice gives the students a relief that "learn to use, and a sense of accomplishment". In this way, the understanding of theoretical knowledge and learning effect of students would be improved. To further enhance the students' practical application and innovation ability, it is essential to organize students to participate in all levels of electronic design competition and physics and experimental science and technology innovation competition for the universities of Jiangsu province and other subject competitions, which are featured with high-intensity baptism and rigorous professional comments. Through these processes, the spirit of craftsmen "technology from the accumulation, success stems from the dedication ${ }^{[1] " ~ w o u l d ~ b e ~ r e c o g n i z e d ~ b y ~ s t u d e n t s . ~}$

\subsection{Reform the training programs, curriculum system and assessment methods}

Combined with school requirements and faculty professional characteristics, for the purpose of strengthening the students' comprehensive quality, the spirit of innovation and practical ability, some subject courses have been deleted with plan and goal step by step in the revision of the professional teaching plan for the nine consecutive years from 2008 to 2016. According to the fundamentals of person-oriented, scientific planning, reflecting the characteristics, dynamic development, adhere to innovation and so on, following the rules of curriculum learning, the subject courses were set up reasonably. Furthermore, on the basis of the requirements of different professional curriculum system, part of the elective courses have been adjusted to compulsory courses and the order of the theoretical courses and experimental courses, cutting-edge courses and tool application courses have been arranged in the logic relationship of courses' contents. In order to replace traditional practice teaching model, "doing the routine experiments, submitting an experimental report, participating in experimental operation assessment and closed book examination", there are several solutions as follows. Curriculum assessment methods are extended to book-opened examination test, process assessment, reading reports, project-design and thesis defense. The actual project background content and other curriculum assessment content reform can be enriched. Integrated design experiments, research and exploration projects can be carried out. Diversification development of students and their ability shall be improved in the experience of access to information, designing system programs and technical routes, component selection, schematic design, PCB design and production, application preparation, system prototype testing, writing summary report and participating in the subject acceptance and so on ${ }^{[2]}$. 


\section{CHARACTERISTICS OF THE PROPOSED TRAINING MODE}

\subsection{Highlight student subjectivity}

Student - centered training model, which is characterized by respect for students' nature and inner needs, focusing on the realization of their self-worth. This model emphasizes stimulating and cultivating students' subjective consciousness in teaching, deepening students' understanding of knowledge, thought and cultural connotation, cultivating their learning ability and innovative thinking habit, making them aware of their status, task, value and function. Then, learn passion of students will be inspired and learning ability will be improved which make them become the master of learning. Accordingly, the students form a correct view of the world and values gradually and eventually become elite talent with lofty ideals and aspirations.

\subsection{Emphasize the cultivation of innovative thinking ability}

Student-centered training mode advocates the teacher's "teaching" to serve the students "learning". This mode focuses on the use of discussion, heuristic, inquiry and other flexible teaching methods in the teaching process. Students are trained to identify problems, solve problems, innovative thinking and comprehensive practice and other capability in this mode. Student-centered training mode guides students to take the initiative to learn, actively participate into the independent development, through the establishment of professional related popular technology and problems, carrying out group cooperation, organizing the exchange of discussion, writing academic reports, replying and presentation and other segments. The capability of review literature skills and how to analyze, summarize and solve problems will be trained. The critical thinking and imagination will get exercise. In addition, the students are encouraged to read extensively and form a diversified knowledge structure to effectively improving their innovative thinking ability, because "innovative talents are not taught by teachers ${ }^{[3] " .}$

\subsection{Strengthen the construction of practical links}

In the process of exploring a training mode of engineering innovation talents, we took the reform of teaching system as the breakthrough point, through the system design, stratifying basic course experiment, curriculum design experiment, professional social practice and graduation practice, graduation design (thesis) and other aspects of practice. Several approaches for setting up a three-dimensional practice teaching system, which support and promote each other, can be summarized as follows: combination of routine experiments and opening experiments, combination of experimental teaching and scientific research, combination of experimental courses and industry practice, combination of independent design and cooperative inquiry, combination of competition design and product development, and other methods. So as to further provoke students' interest in learning, promote their independent thinking and exploration, and profoundly appreciate the value of knowledge and the joy of creation, it is necessary to make full use of the leading role of practical teaching in the cultivation of students' engineering innovation ability.

\subsection{Attach importance to personality differences}

For the teachers, the proposed engineering personnel training model based on the undergraduate tutor system is conducive to find each student's flash point. Thus, according to the different characteristics of students and personality differences, the individualized teaching and diversified development guidance are provided to cultivate their talents for all walks of life in order to fully tap the advantages of personality potentials. Meanwhile, by paying attention to the growth of students in morality, knowledge, talent, learning, etiquette and many other factors in harmony, the spirit of moral literacy, scientific and cultural literacy and physical quality and other comprehensive development are promoted.

\subsection{Focus on the effectiveness of curriculum reform}

Curriculum system is the main carrier of university personnel training, the bridge between teaching ideas and practice, reflecting the school characteristics and personnel training objectives at the same time. According to the fundamentals of person-oriented, scientific planning, reflecting the characteristics, dynamic development, adhere to innovation and so on, following the rules of curriculum learning, the subject courses were set up reasonably, in view of meeting the needs of modern engineering innovation talent training, actively cultivating students' comprehensive quality and innovative spirit, as well as the ability to analyze and solve problems, adapting to competition, communication skills and lifelong learning and other aspects of the ability. Meanwhile, Curriculum assessment methods are extended to book-opened examination test, process assessment, reading reports, project-design and thesis defense. The actual project background content and other curriculum assessment content reform can be enriched, which focus on inspiring and guiding the reform of assessment content in order to ensure the effectiveness of curriculum reform, and achieving the evaluation process from 
the form to the full implementation, leading the assessment from the teacher dominant to the participation of teachers and students, the assessment content from theoretical knowledge to the comprehensive ability and evaluation methods from single to multiple.

\section{ACHIEVEMENTS OF THE PROPOSED TRAINING MODEL}

\subsection{Enhanced students' self - learning awareness and practical ability}

Through the implementation of training programs and curriculum system optimization, assessment reform and undergraduate tutor system and a series of initiatives, not only the students' interest in learning, self-learning spirit and innovation awareness are provoked effectively, but also the students' practical awareness is increased significantly and the student's learning attitude has changed greatly, from never concerning about the learning content to actively answer questions in the classroom and communicate with teachers about difficult problems, from seldom writing homework to complete it independently, and from conducting experiment perfunctorily to design independent innovation experiment. Therefore, school's atmosphere of academic and teaching has been improved significantly. Meanwhile, a number of courageous, innovative students take part in the proposed programs actively each year, producing a batch of outstanding prototypes with professional characteristics, such as intelligent DC micro-ohmmeter, high-precision digital perpetual calendar with automatic time service, digitally-controlled high-precision DC power supply with adjustable output voltage, photovoltaic charging controller with the function of MPPT, as shown in Figure 1 to Figure 4.

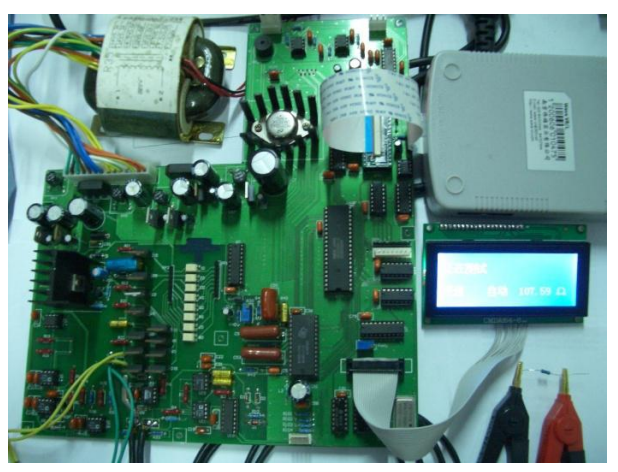

Figure 1. Intelligent DC micro-ohmmeter.

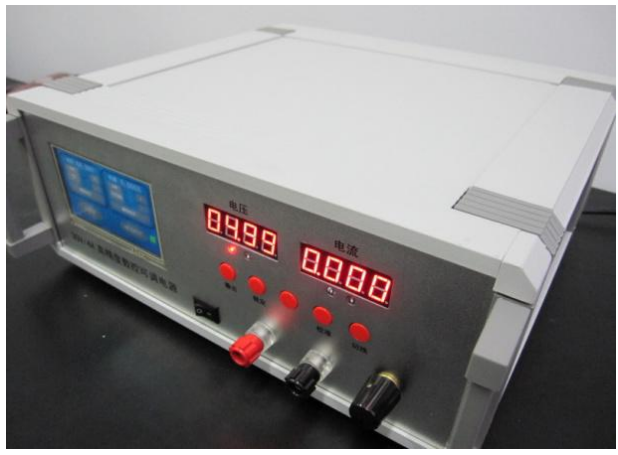

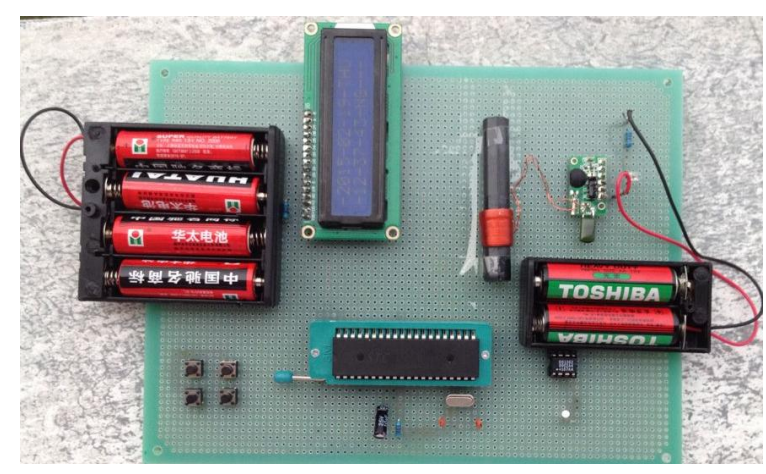

Figure 2. High-precision digital perpetual calendar.

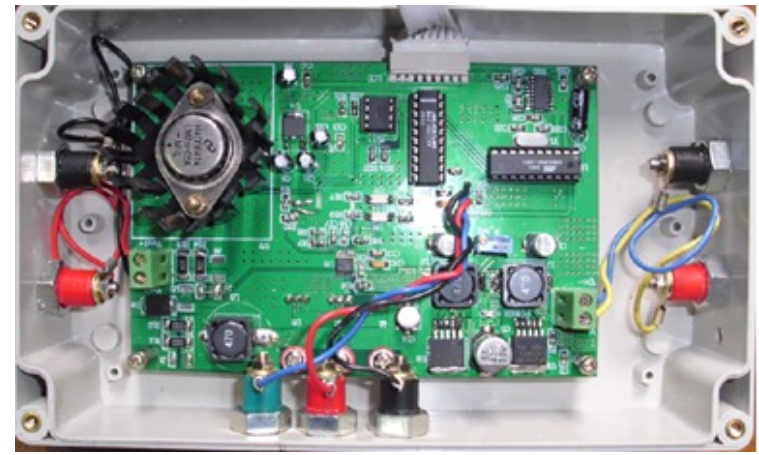

Figure 3. Digitally-controlled high-precision DC power supply. Figure 4. Photovoltaic charging controller.

\subsection{Improved professional construction level}

Relying on the professional foundation and periodical achievements through the implementation of teaching reform, the major of optoelectronic information science and engineering was selected as the Jiangsu province colleges and universities specialty professional construction point in 2010, and passed through the acceptance check with the excellent result in 2012. The major of optoelectronic information science and engineering and the major of electronic information science and technology were selected as the excellent engineers (software) education and training programs in Jiangsu province in 2012, which could further promote the proposed reform of talents training mode and continuously enhance the students' social responsibility, innovation consciousness and engineering practice ability ${ }^{[4]}$. 


\subsection{Improved schools' accreditation and social reputation constantly}

In the innovative talents training mode based on the undergraduate's tutorial system, teachers adhering to the "ingenuity" cultivate a large number of outstanding undergraduates through the mainline of "innovative training program or tutor's research project $\rightarrow$ academic competition $\rightarrow$ graduation projects (thesis)". These excellent graduates all have excellent performance whether in the domestic research, employment, study abroad or entrepreneurship, and their excellent performance and comprehensive quality also make the quality of our education and teaching mode received popular recognition from the graduates' parents and employers. Thus, the social reputation of our university and the first volunteer rate of relevant majors are improving continuously in recent years.

\section{CONCLUSIONS}

The periodical achievements of the recent years' exploration and practice have illuminated that the proposed talents training model can effectively provoke the students' self-learning awareness and enthusiasm, realize the transformation from teachers' teaching to self-learning, from the classroom-centered mode to the combination of classroom and extracurricular activities, and the ability evaluate from only scores of some tests to the combination evaluation of the result and process. At the same time, the proposed talents training model could make part of the "candidates" which were limited to the scope of the examination become into a real "students", make part of the "audience" become into "actor", "screenwriter", or even "director". Thereby, the students' comprehensive practical abilities and the quality of talents training have been improved effectively, promoting the all-around development of students, which will make them become into the elite talents with lofty ideals and ambition.

\section{ACKNOWLEDGEMENTS}

This work was supported by 2015 teaching reform research project in higher education of Soochow University (youth project) and by $3^{\text {th }}$ teaching research project about hot and difficult issues in higher education for specialty in optoelectronic information science and engineering of the Chinese colleges and universities.

\section{REFERENCES}

[1] Zhang, J., [Craftsmen notes: a microcontroller worker practice and thinking], Beihang University Press, Beijing, (2008).

[2] Lin, Y. F., Wang, X. P., Liang, Y. Y., Wang, K. W., and Zheng, X. D., "Practice and effect of teaching method reform about changing from classroom-centered mode to the combination of classroom and extracurricular activities," Journal of Higher Education Research, Vol. 37, No. 3, 70-74 (2014).

[3] Li, Z. H., Luo, X., "Academician of the Chinese academy of sciences, mathematician Wang Yuan: 'Innovative talent is not taught out'," Guangming Daily, 6 December 2014.

[4] Xu, Y. S., Wu, D., Chen, D. Q., Gu, J. H., Tao, Z., and Gao, L., "Exploration and practice of cultivating engineering innovative ability of college students - taking Soochow University as an example," Theory and Practice of Contemporary Education, Vol. 7, No. 11, 44-46 (2015). 